\title{
A saúde no sistema de seguridade social brasileiro
}

Potyara A. P. Pereira*

Resumo: O objetivo central deste artigo é examinar as tendências recentes da proteção à saúde no Brasil, no marco da Constituição Federal de 1988. Pretende-se demonstrar que, apesar de a saúde fazer parte do Sistema de Seguridade Social, inaugurado por esta Constituição, ela não se realizou de forma integrada às demais políticas que compõem - Sistema e nem produziu as reformas pretendidas. Pelo contrário, por contrariar interesses privados e conservadores, a concepção de saúde como direito de todos foi atingida por uma onda contra-reformista, surgida nos anos 1990, com o apoio do Executivo federal. Hoje, a política de saúde carece de uma nova coalizão de forças para transformar-se numa questão capaz de devolver-lhe o caráter público e a vinculação com a cidadania.

Palavras-chave: política de saúde, sistema de seguridade social Constituição de 1988.

\section{Introdução e contextualização do problema}

O propósito deste artigo é fazer um balanço crítico das recentes tendências da proteção à saúde no Brasil, à vista dos preceitos contidos na Constituição da República vigente, promulgada em 5 de outubro de 1988, que tratam do Sistema de Seguridade Social. Este Sistema, por sua vez, será analisado no marco das mudanças que engendraram esses preceitos constitucionais, tidos

Professora do Departamento de Serviço Social da Universidade de Brasília e Coordenadora do Núcleo de Estudos e Pesquisas em Política Social do Centro de Estudos Avançados Multidisciplinares da Universidade de Brasília (NEPPOS-CEAM/UnB). 
como democráticos, e confrontado com a chamada "onda contrareformista", surgida nos anos 1990 com o intuito de desmontá-lo.

Registre-se, inicialmente, que a Constituição de 1988 introduziu significativos avanços no ordenamento legal brasileiro, ampliando direitos e corrigindo iniqüidades. Tais avanços tiveram particular relevância no âmbito da Seguridade Social - um conceito até então ausente na legislação e na experiência nacionais de proteção pública.

Compreendendo "um conjunto integrado de iniciativas dos Poderes Públicos e da Sociedade, destinadas a assegurar os direitos relativos à saúde, à previdência e à assistência social" (art. 194, caput), a Seguridade ganhou conotação mais ampla ao unir, nos seus arts. 194 a 204, do Capítulo 2, do Título VIII, da Ordem Social, ações distributivas com a tradicional prática contributiva previdenciária, adotada pelo Estado desde os anos 1930. É por isso que se diz que o Sistema de Seguridade Social, instituído formalmente no país, em 1988, pretendeu unificar três políticas em torno de dois eixos diferenciados: um, contributivo, representado pela previdência e, outro, distributivo representado pela saúde e assistência social.

Ao integrarem e fortalecerem o lado distributivo da Seguridade Social, a saúde e a assistência revolucionaram o padrão convencional de proteção pública no Brasil por três motivos principais:

a) A segurança social dos cidadãos passou a ser, a partir de então, concebida independentemente de prévias contribuições e inserções no mercado de trabalho, ou de posses privadas de renda. Estava implícito, nessa concepção, o princípio da desmercadorização que desvincula a política social da lógica do mercado e da ética capitalista do trabalho, para comprometê-la com o dever cívico da satisfação de necessidades sociais;

b) As políticas de saúde, previdência e assistência fariam parte de uma nova institucionalidade, cuja principal característica seria a unidade conceitual e estratégica de suas diferentes ações. Sendo assim, a noção de Seguridade teria de extrapolar o caráter contratual de seguro da política de previdência, para expressar, por meio da 
saúde e da assistência, a idéia de prestação incondicional de atendimento, tendo como único parâmetro o status de cidadania;

c) A cidadania social assumiria, por conseqüência, caráter extensivo, guiado pelos princípios da incondicionalidade e da universalidade. Tais princípios, na saúde, expressariam um significado altamente diferenciador em relação ao passado, pois visariam ao acesso igualitário e sem contrapartida de todos aos bens e serviços disponíveis. Foi sob a égide desses princípios que os legisladores definiram na Constituição (art. 198), uma rede integrada, descentralizada e hierarquizada de saúde, constituída de um sistema único nacional (mais tarde conhecido como SUS) a ser operado em cada esfera federada de governo (União, Estados e Municípios). Já na assistência social, a incondicionalidade implícita na idéia de gratuidade estaria associada à universalidade de forma indireta, pois a principal função desta política é a de ampliar as condições de acesso a bens e serviços públicos de grupos particulares (os tradicionalmente excluídos do acesso a esses bens e serviços). Daí porque, embora diferenciadas quanto à sua atenção e ao seu destinatário, tanto a saúde, quanto à assistência, passaram a constituir, incondicionalmente, um dever de prestação do Estado e um direito de crédito dos cidadãos (Pisón, 1998), funcionando como contraponto à lógica securitária.

São os princípios da incondicionalidade e da universalidade, portanto, que se destacam no Sistema de Seguridade Social brasileiro, não só como elementos inovadores por excelência, mas como desafios fundamentais à concepção liberal de cidadania referenciada no interesse pessoal e nas determinações do mercado. É que estes princípios privilegiam direitos sociais e difusos que, por serem gerais, vinculam-se à justiça sociale impõem, adicionalmente, limites às liberdades negativas, típicas dos direitos individuais, bem como à focalização e à comercialização das políticas públicas.

Em vista disso, a Constituição previu a organização da Seguridade Social com base nos seguintes objetivos (Parágrafo único do art. 194 e seus respectivos incisos), que se vinculam, com algumas diferenciações, às três políticas: 
I - universalidade da cobertura e do atendimento (saúde);

II - uniformidade e equivalência dos benefícios e serviços às populações urbanas e rurais (saúde, previdência e assistência);

III - seletividade e distributividade na prestação dos benefícios e serviços (assistência);

IV - irredutibilidade do valor dos benefícios (saúde, previdência e assistência);

V-eqüidade na forma de participação do custeio (previdência);

VI - diversidade da base de financiamento (saúde, previdência e assistência);

VII-Caráter democrático e descentralizado da gestão administrativa, com a participação da comunidade, em especial dos trabalhadores, empresários e aposentados (saúde, previdência e assistência).

Como instrumento de integração efetiva do Sistema, tanto no que concerne à sua conceituação quanto ao seu planejamento, coordenação e financiamento, também foi previsto na Constituição (art.195) o Orçamento da Seguridade Social (OSS) com fontes definidas de recursos. A concepção desse Orçamento, apoiada numa composição de receitas fiscais - constantes dos orçamentos das três esferas federadas de governo - e nos recursos provenientes de contribuições sociais e de concursos de prognósticos, significou, em tese, um comprometimento governamental com o financiamento regular e previsível das três políticas que compõem o Sistema.

Ademais, são dignas de nota importantes preceituações constitucionais referentes à organização e à gestão políticoadministrativa das políticas de Seguridade Social, como as que prevêem: a) descentralização das ações, com ênfase na municipalização; b) controle público ou democrático das decisões e das práticas governamentais e privadas; e c) participação direta, ou semidireta, da população na formulação das políticas e na execução das ações, por meio de instituições e mecanismos específicos, especialmente os Conselhos decisores e gestores presentes em cada esfera da Federação. 
Contudo, todas essas disposições constitucionais, fruto de notável mobilização e influência de parcelas representativas da sociedade, que queriam tornar o país contemporâneo dos modernos Estados de Bem-Estar, não eram auto-aplicáveis. A sua aplicação dependia de regulamentação por leis ordinárias, elaboradas para este fim, nas quais estariam consignados os desdobramentos e interpretações do conteúdo conciso da Carta Magna. Isso, por si só, indicava que, entre a intenção dos legisladores e a aplicação dos dispositivos constitucionais, havia um espaço político-decisório cujo preenchimento prenunciava novas mobilizações e embates.

De fato, a ausência de auto-aplicação de vários desses dispositivos - dentre os quais os referentes à Seguridade Social expôs uma característica da Constituição de 1988, reveladora de tensões não resolvidas na Assembléia Constituinte (ou Congresso Constituinte, como seria mais adequado dizer). Trata-se, na expressão de Reale (apud Macedo, 1990, p. 61), do caráter conflitual desta Constituição, pois, entre outros aspectos, todos os avanços polêmicos nela contidos foram tratados de forma genérica e remetidos à legislação complementar ou ordinária para a sua efetivação. Esta foi, sem dúvida, a estratégia encontrada pela maioria dos legisladores constituintes para adiar definições políticas cujos impasses poderiam comprometer o andamento do processo de redemocratização do país; mas, também, foi essa estratégia que abriu brechas para que o poder constituído, especialmente o Executivo Federal, se eximisse de responsabilidades quanto à integralização e efetivação do Sistema, sob a alegação de ausência de leis.

Com efeito, é fato empírico que o processo de regulamentação das matérias constitucionais referentes às políticas componentes do Sistema de Seguridade Social, constituiu uma nova etapa de agudos conflitos agudos de interesses e fator de desagregação do Sistema. Identificadas com direitos sociais (que exigiam decisiva intervenção do Estado), numa época já contaminada pelo ideário neoliberal (que exigia a retração da ação estatal), tais políticas tiveram o seu reconhecimento público dificultado. Se se levar em conta, ainda, a arraigada cultura anticívica da elite brasileira e o precário legado histórico da democracia nacional, entender-se-á porque o conceito concertado e orgânico de Seguridade Social, previsto na Constituição, 
nunca se materializou na prática. E mais: entender-se-á porque, desde o período constituinte, esse conceito foi veementemente questionado sob o argumento, avalizado oficialmente, de tornar o país ingovernável, devido aos gastos excessivos que ele imporia aos cofres públicos.

Todavia, ultrapassando esse entendimento, uma análise mais acurada revela que, realmente, o que estava em jogo não era tanto a incompatibilidade dos avanços constitucionais com a ascensão do neoliberalismo e nem mesmo uma provável crise financeira do Estado. De fato, estava em jogo, a possibilidade de ruptura desses avanços com os tradicionais esquemas de barganha populista e de patronagem política, os quais mantêm velhas oligarquias no poder e inibem a extensão da cidadania. Tanto foi assim que o Executivo e o Legislativo postergaram deliberadamente gestões para a aprovação final dos dispositivos constitucionais referentes à matéria e criaram lapsos temporais diferentes entre a promulgação da Constituição e a implementação dos direitos à seguridade. Por isso, só em setembro de 1990 a Lei Orgânica da Saúde foi promulgada, e somente em julho de 1991 as leis de Organização e Custeio e de Benefícios da previdência receberam sanção presidencial. Fato singular foi o Projeto de Lei Orgânica da Assistência, que após receber, veto integral do Presidente da República (Collor de Mello), em 1990, só foi promulgada em dezembro de 1993, mediante reiterada pressão social.

Tal fato reforçou as condições desfavoráveis à implantação, no País, de um Sistema de Seguridade que, ao menos, articulasse três políticas sociais. Em decorrência, a par da tradicional setorização das políticas públicas brasileiras, criou-se, a partir da regulamentação parcelada e descoordenada do Sistema, um hibridismo na concepção e ação das políticas que o compõem, dadas a justaposição dos dois eixos que deveriam estruturá-lo organicamente (contributivo e distributivo) e a desarticulação das três políticas.

Isso posto, veja-se a seguir a trajetória do processo de ressignificação da política de saúde num contexto de negação do seu status legal de componente da Seguridade Social. 


\section{O perfil formal da saúde como política de seguridade social}

No Brasil dos últimos trinta anos, a saúde assumiu papel de destaque dentre as políticas sociais pela consistente reivindicação de seus atores estratégicos por mudanças.

Imprimindo a esse movimento uma direção contestadora dos efeitos deletérios do padrão centralizador de proteção à saúde do período ditatorial (1964-1985), várias forças representativas da área formaram, na década de 1970, uma coalizão presidida pelo ideário de uma Reforma Sanitária. A difusão desse ideário - que foi acompanhada de realizações programáticas, como o Plano de Interiorização das Ações de Saúde e Saneamento (Piass) ${ }^{1}$ - teve como principais propagadores instituições como o Centro Brasileiro de Estudos em Saúde (Cebes), criado em 1976, "a partir da iniciativa de filiados do então Partido Comunista do Brasil (PCB)" (Elias, 1997, p. 195). Além do Cebes, é digna de nota a participação de profissionais e políticos de esquerda, com articulações internacionais, bem como de membros de centrais sindicais, de entidades associativas de trabalhadores da área e de movimentos populares. Grande parte dos profissionais mencionados ocupava postos importantes no Ministério da Saúde (MS) e no Instituto Nacional de Assistência Médica da Previdência Social (Inamps) - o que Ihes propiciava conhecimento da máquina governamental e, conseqüentemente, condições privilegiadas para problematizar a situação da saúde e incluí-la, como questão politicamente trabalhada, na agenda pública. Tratava-se, portanto, de uma elite profissional, de atores estrategicamente situados, dotados de recursos políticos para transformar problemas em questão (Oszlak e O'Donnell, 1976), a ponto de angariarem para as suas propostas ampla legitimidade. Disso se ressentiu a previdência e, especialmente, a assistência social, a qual, nas palavras de Almeida (1996, p. 25), não contou com "uma elite profissional que fosse capaz de nuclear e dar rumo a uma coalizão mudancista e que aliasse clara concepção do novo modelo

O Piass era um programa interministerial coordenado pelo Ministério da Saúde, que, segundo Medici (1996, p. 299), "foi assumindo progressivamente a unicidade de comando do sistema (...). Tinha como objetivo implantar uma estrutura básica de saúde pública nas regiões onde inexistiam condições mínimas para tal (...). Além de envolver o esforço conjunto dos governos federal, estadual e municipal, contava com a participação social." 
assistencial com experiência de gestão pública e forte penetração nos centros de decisão da política assistencial no Executivo".

Nasceu, assim, o movimento de Reforma Sanitária, que teve grande atuação na VIII Conferência Nacional de Saúde, realizada em 1986, a qual, por sua vez, exerceu ponderável influência na Assembléia Nacional Constituinte, de 1987. Segundo Bravo (2000, p. 109), "a VIII Conferência, numa articulação bem diversa das anteriores, contou com a participação de 4.500 pessoas, dentre as quais mil delegados". Além disso, prossegue Bravo, o evento marcou uma inflexão nas tendências do debate na área, pois relacionou a saúde à sociedade, ampliando as dimensões de seus foros específicos e de seus limites setoriais.

Não por acaso, a saúde ganhou na Constituição uma seção mais detalhada no Capítulo da Seguridade Social do que as suas congêneres. Nessa seção estão contidas muitas das bandeiras defendidas pelo movimento da Reforma Sanitária, a saber: concepção da saúde como direito de todos e dever do Estado; acesso universal e igualitário às ações e serviços; relevância pública da política; comprometimento do Estado com a sua regulamentação, fiscalização e controle; integração das ações compondo um sistema único de atendimento; descentralização das decisões e ações da esfera federal de governo para a estadual e municipal, com comando único em cada esfera; atendimento integral, com prioridade para as atividades preventivas, sem prejuízo dos serviços assistenciais; participação da comunidade na formulação e no controle da política.

Entretanto, como já observado, a consignação dessas bandeiras reformistas na Carta Magna, não se deu sem tensões e contendas. A discussão sobre a saúde na Assembléia Nacional Constituinte, transformou-se em uma arena real de conflitos de interesses, na qual, conforme Bravo (2000, p. 109), dois conjuntos de forças antagônicos passaram a confrontar-se: os grupos privados empresariais prestadores de serviços ou ligados à indústria farmacêutica, de um lado, e os adeptos da Reforma Sanitária, de outro lado.

Os primeiros, caudatários do modelo médico-assistencial privado (Bravo e Matos, 2001, 2000), tinham e têm no mercado o seu principal agente regulador, e na rentabilidade econômica a 
sua meta prioritária. São os defensores da ingerência mínima do Estado na economia e na sociedade e, conseqüentemente, da mercantilização de bens públicos como a saúde. Trata-se, portanto, de uma defesa corporativa, segundo a qual a descentralização político-administrativa como um dos principais meios estratégicos de transição das práticas autoritárias para as democráticas, se vê prejudicada; pois, o sentido de descentralização para estes grupos tem mais a ver com a desregulamentação da economia - para torná-la mais competitiva - e com a privatização dos bens e políticas públicos (Pereira-Pereira, 1998). Sendo assim, não há lugar para a realização dos princípios da incondicionalidade e da universalização, como fundamentos do SUS.

Em contraposição, os adeptos da Reforma Sanitária defendiam e defendem a instituição de uma política deliberada e radical de descentralização, mediada pelo SUS, visando a transferência de capacidades decisórias do governo central para os Estados e especialmente para os Municípios. E na base dessa política existia um propósito deliberado e contínuo de promover mudanças que garantissem não apenas um atendimento igualitário, mas igualdade com eqüidade nesse atendimento. Isso porque, num país onde imperam profundas e seculares desigualdades, o tratamento apenas igualitário, subjacente ao princípio da universalização, acabaria por manter e perpetuar as desigualdades prevalecentes. A esse respeito é famosa a frase de Marx quando, ao referir-se ao direito burguês, proclama: "todo direito consiste na aplicação de uma regra única a homens diferentes, que, de fato, não são nem idênticos, nem iguais. Sendo assim, o direito igual equivale a uma violação da igualdade, a uma injustiça" (Marx, 1975, p. 17).

Esta foi a razão porque o preceito da eqüidade, segundo o qual as ações públicas devem privilegiar as classes menos aquinhoadas economicamente, ganhou relevo nas alas progressistas da saúde, muitas vezes sob a discutível denominação de discriminação positiva.

No que diz respeito à regulamentação da saúde, a Constituição a previa para 1989, logo após a sua promulgação, de par com a regulamentação da previdência e da assistência. Mas, devido aos conflitos de interesses e à falta de vontade política mencionados, isso 
só ocorreu em 1990, com a promulgação da Lei 8.080, - "conhecida como Lei Orgânica da Saúde -, [que] define as atribuições de cada esfera de governo no que diz respeito à gestão e competências" (Arretche, 2000, p. 205) - e da Lei 8.142, que, complementando a primeira, "estabelece as formas de participação comunitária e as condições e formas de transferências de recursos entre as esferas de governo" (idem). A existência das duas leis deve-se ao fato de a primeira ter sofrido mutilações, sob a forma de vetos presidenciais em vinte e cinco itens, especialmente nas partes referentes ao financiamento e ao controle da política, o que exigiu a elaboração da segunda lei para complementá-la (Bravo e Matos, 2000, p. 202; Fagnani: 1997). ${ }^{2}$

Isso revela com clareza a conjunção de obstáculos estruturais e conjunturais impostos à pretensão das políticas sociais brasileiras de se tornarem letras vivas na lei. A agravar essa tendência, tem-se que, a onda neoliberal, disseminada pelo mundo capitalista a partir da Grã Bretanha e dos Estados Unidos da América, desde os anos 1970, difundiu uma concepção de Seguridade que vem resgatando o velho modelo alemão bismarckiano do século XIX, baseado no seguro, em oposição ao modelo inglês beveridgiano, dos anos 1940, baseado na ampliação da cidadania. Em vista disso, orientações centradas na lógica atuarial e contábil, na competitividade privada e no equilíbrio macroeconômico, passaram a prevalecer em detrimento de qualquer intenção de privilegiar a satisfação de necessidades sociais.

Como é óbvio, os princípios da incondicionalidade e da universalidade viram-se profundamente afetados, já que Ihes retiraram as condições materiais e políticas de realização. E a rígida

\footnotetext{
2 Semelhantes atentados aconteceram no âmbito da previdência e da assistência social. $\mathrm{Na}$ assistência, como já assinalado, o Projeto de Lei encaminhado pelo Congresso Nacional para sanção do Presidente da República, foi integralmente vetado, exigindo a elaboração de um novo Projeto, que consumiu mais três anos de articulações políticas. Na previdência, inicialmente houve uma tentativa de desvincular os benefícios previdenciários do valor do salário mínimo, contrariando o art. 58, das Disposições Transitórias, da Constituição. Depois, em 1990, houve desacordos entre os Poderes Legislativo e Executivo quanto aos planos de benefícios e de organização e custeio da seguridade social, traduzidos em vetos presidenciais e derrubadas de vetos no Parlamento. Assim, somente em julho de 1991, o Plano de Benefícios da Previdência Social e o Plano de Organização e Custeio da Seguridade Social foram regulamentados (com distorções), respectivamente pelas Leis $n^{\circ}=8.212$ e no 8.213 .
} 
contenção dos gastos públicos, que normalmente acompanha essas restrições, contribuiu decisivamente para inviabilizar a efetivação do conceito integrado de Seguridade Social no Brasil.

Foi nesse cenário adverso que a Lei Orgânica da Saúde (LOS) procurou afirmar e aprofundar os preceitos constitucionais a ela pertinentes. Elegendo o SUS como a sua principal referência, a LOS colocou sob a regência do Sistema Único toda a política da área, a qual, para a sua realização, prevê a inter-relação do atual redesenho do pacto federativo com canais institucionais de participação social e mecanismos de gestão democrática, compreendendo:

a) Conferências realizadas periodicamente para avaliar a política em andamento e fornecer recomendações para os anos próximos vindouros;

b) Conselhos deliberativos e paritários, de representação descentralizada e participativa entre Estado e sociedade, para aprovar a política de saúde, elaborada pelo Órgão Gestor, e acompanhar e fiscalizar a sua execução substantiva e orçamentária;

c) Órgão Gestor, responsável pela formulação e gestão da política e dos planos de saúde, com base nas recomendações das Conferências, bem como pelo seu comando único em cada unidade da federação, evitando-se superposições de direções;

d) Fundo especial, para alocar recursos financeiros específicos e servir de canal de transferência regular e automática desses recursos entre as esferas de governo, para financiar as suas ações.

As dificuldades de operacionalizar esse sistema, ao mesmo tempo unificado, descentralizado, equânime e participativo, exigiu a posterior construção de engenharias administrativas traduzidas como Normas Operacionais Básicas do SUS, editadas pelo governo federal por meio do Ministério da Saúde.

A primeira dessas Normas, criada em 1991 (NOB-SUS no 01/91), não conseguiu romper com o velho hábito de encarar os gestores estaduais e municipais como meros prestadores de serviços (Cunha, 2000, p. 97). Tal procedimento só começou a se modificar com a NOB 
de 1993, que resultou de um intenso processo de negociações entre o governo e representantes do movimento sanitarista insatisfeitos com a demora da implementação do SUS (Arretche, 2000, p. 206). Por esta NOB foram criadas Comissões Tripartites e Bipartites de gestores, até hoje existentes, com o objetivo de implementar o processo de gestão descentralizada do SUS. Deu-se início, assim, à sistemática de repasse direto - de fundo para fundo - dos recursos financeiros da esfera federal para a municipal (em contraposição à antiga e fisiológica prática convenial) e ao exercício da autonomia do Município como gestor de suas políticas.

Em 1996, outra NOB foi editada, com vigência até hoje, a qual, segundo Bravo e Matos (2001, p. 209), tem forte inclinação focalizadora e desarticuladora. Nela, estão previstas duas condições de gestão descentralizada: a gestão plena do sistema de saúde e a gestão plena da atenção básica. Segundo Souza, Monnerat e Senna (2000, p. 73) a diferença principal entre essas duas modalidades é que, na primeira, o Município gerencia autonomamente todo o atendimento à saúde local, inclusive a rede hospitalar privada, enquanto, na segunda, ele administra apenas a rede de atendimento básico. Com isso, pretendeu-se melhor definir as condições de habilitação dos Municípios em duas áreas de gestão, dividindo-se conseqüentemente o SUS em duas partes: uma, de referência, para os que podem pagar pelos serviços de saúde, e, outra, básica, focalizada nos pobres.

Entretanto, "em que pese o arcabouço básico da saúde estar praticamente concluído desde os anos 1990, tornando-se a primeira (...) dentre as áreas sociais a ter completa a sua regulamentação (...), suas conseqüências não surtiram os efeitos previstos e desejados em grau e velocidade compatíveis com as exigências para a estruturação do SUS” (Elias, 1997, p. 205), conforme será visto a seguir.

\section{Entraves conservadores à implementação do SUS}

Os desafios impostos à estruturação do SUS fazem parte de um movimento amplo, contrário à ampliação dos direitos sociais no País desde a fase da Assembléia Nacional Constituinte, denominado por vários analistas de contra-reforma conservadora. 
Para Fagnani (1997, p. 87), portanto, tal contra-reforma teve a sua gestação no período compreendido entre 1987 e 1990, da chamada "Nova República", sob o governo Sarney, a qual foi definida como a transição democrática.

Foi nesse período, pois, que se formaram as resistências às propostas progressistas no âmbito das políticas sociais, a partir do rompimento da coalizão governista feita em prol da redemocratização. ${ }^{3}$

O principal sinal de ingerência contra-reformista nos rumos das políticas sociais foi a primazia dada pelo governo aos seguintes procedimentos:

a) privilegiamento do assistencialismo e do clientelismo nas ações estatais. O exemplo mais notório dessa tendência foi a realização de ações pela Secretaria Especial de Ação Comunitária (Seac), vinculada à Presidência da República, que se mostraram "pulverizadas e permeáveis à cooptação fisiológica e clientelísta” (Melo, apud Fagnani, 1997, 86). Essas ações, cujo lema era o da participação comunitária e da descentralização, realizavam-se por meio de convênios diretos entre o governo e entidades privadas, de caráter popular;

b) o esvaziamento das propostas e estratégias reformistas, seja pela lentidão decisória do governo central, seja pelo descumprimento deste governo dos mandamentos constitucionais. Foi o caso da falta de empenho do Executivo em cumprir o prazo definido pela Constituição para a regulamentação do capítulo da Seguridade Social; ${ }^{4}$

c) o desmonte orçamentário na área social, sob o pretexto de ajustamento do Orçamento da União às mudanças instituídas pela Constituição. Conhecida como "operação

\footnotetext{
3 'Nesse período ocorre a fragmentação da Aliança Democrática e as lideranças 'históricas' do PMDB [Partido do Movimento Democrático Brasileiro] foram deslocadas de pontos estratégicos do Executivo" (Fagnani, 1997, p. 86).

4 A Constituição, no art. 59 do Ato das Disposições Transitórias, estabelece que o Executivo teria um prazo máximo de seis meses, a partir da sua promulgação, para encaminhar ao Congresso Nacional os projetos de regulamentação da Seguridade Social. O Congresso, por sua vez, teria igual período para apreciar referidos projetos.
} 
desmonte", tal ajustamento ensejou uma série de cortes drásticos em programas sociais, geridos centralizadamente pelo governo, com a justificativa de descentralizá-los;

d) a relutância governamental em efetuar as reformas determinadas pela Constituição, por considerá-las fatores de ingovernabilidade. Essa relutância foi acompanhada de manobras do Executivo para retardar a implementação dos novos direitos e quebrar a organicidade do conceito de Seguridade Social, inviabilizando-a. Um alvo privilegiado dessa tendência, foi o Orçamento da Seguridade Social, o qual, conforme será visto adiante, sofreu graves distorções e desvirtuamentos de sua finalidade.

Tem-se, assim, a partir de 1990, o estabelecimento de uma trincheira contra-reformista impeditiva dos avanços no campo da Seguridade Social, com o aval do governo central. E essa trincheira tinha a respaldá-la a ofensiva neoliberal que encontrou no país fatores condicionantes, a saber: um governo simpático às teses neoliberais e articulador de forças conservadoras; a aceleração inflacionária, não obstante os intentos governamentais de dominála com fugazes planos de estabilização e ajustes recessivos; e a chamada crise do setor público.

Esse conjunto de fatores teve repercussões contundentes nos rumos das políticas sociais.

Dentre os alvos preferidos do ataque neoliberal, ressalta o SUS com a sua proposta inovadora de descentralização e universalização. Como era previsível, essa proposta teve interpretação espúria e realização "caótica" (Viana, 1996), ${ }^{5}$ com grande permeabilidade à participação dos setores privados e a práticas demolidoras de sua base financeira.

Com efeito, já no início dos anos 1990, o SUS sofreu um considerável desfalque nas suas receitas ao ter grande parte delas usada indevidamente. Pelo menos três grandes sangrias podem ser

5 Para Viana (1996, p. 270), "existem dois tipos de descentralização: a planejada (originalmente formulada no SUS), que envolve a passagem gradativa de funções e recursos; e a caótica (efetivamente observada), na qual se substituem, de maneira abrupta, recursos federais por orçamentos estaduais e municipais, sem que se desenvolvam ou atualizem as funções e atribuições das esferas governamentais". 
apontadas: o pagamento de encargos previdenciários com recursos da Seguridade; a retenção dos repasses das contribuições sociais que financiavam o Sistema (Finsocial, contribuição sobre o lucro, PIS-Pasep) pelo Tesouro Nacional "(Azevedo, apud Fagnani, 1997, 88); e o reajuste dos benefícios previdenciários dos aposentados em $147 \%$, por ordem judicial.

Outro ataque à proposta descentralizada do SUS, ainda no início da ofensiva contra-reformista, foi a recentralização dos pagamentos referentes à saúde no Inamps. A extinção deste Instituto, prevista na reforma administrativa do Ministério da Saúde, para que este se adequasse à Reforma Sanitária, foi postergada por um ano após a sua definição. Da mesma forma, vários órgãos do Ministério, como a Fundação SESP e a Superintendência de Campanha de Saúde Pública (Sucam), relutaram em abrir mão de seus equipamentos e em transferir as suas atividades de prestação de serviços para o nível municipal.

Em 1994, uma outra resistência centralizadora, refratária aos pressupostos do SUS, foi a retenção no Ministério da Saúde das atividades regulatórias, de controle e auditoria dos recursos da área e da compra de serviços privados. Isso criou uma situação em que os Estados e Municípios novamente passaram a ser tratados como simples prestadores de serviços nas suas respectivas esferas de governo (Viana, 1997, p. 272). "Ainda no nível central", ressalta Viana, "um outro bloco de interesses, até mais poderoso do que o do Ministério da Saúde, 'jogava' contra a descentralização. Era o bloco da área econômica, formado por técnicos e dirigentes do Ministério da Fazenda", que efetuava expressivos cortes nos recursos federais destinados à saúde. Para se ter uma idéia da magnitude desses cortes, basta mencionar que, de 1987 a 1992, houve uma queda de $40 \%$ em termos reais dos gastos federais na área; e que, de 1988 a 1993, ocorreu uma diminuição de US\$ 80 para US\$ 40, no gasto federal per capita, sem compensação pela elevação dos gastos estaduais e municipais. Isso, como não poderia deixar de ser, atingiu a espinha dorsal do Sistema que era o reforço federal à implementação de suas novas funções.

No âmbito subnacional, problemas ocorreram devido à resistência dos Estados em transferir equipamentos e recursos para os Municípios, o que ensejou concorrências, em vez de 
complementaridades, entre essas duas esferas da Federação. Muitos Municípios, por seu turno, além de seus parcos recursos orçamentários, tinham e têm dificuldades de exercitar a sua autonomia como entes federados, conforme estabelece, pela primeira vez na história, a Constituição de 1988, e de se livrar da dependência estadual e federal. A isso se acrescenta a defasagem e a desatualização da máquina pública dos Estados e dos Municípios em face dos requerimentos organizacionais e gerenciais do SUS.

Dessa forma, o viés centralizador encontrou ambiente propício à sua reprodução em todos os níveis da Federação e se fortaleceu com as resistências da iniciativa privada, seja a contratada e conveniada ao SUS, seja a autônoma ao Sistema. A primeira, insatisfeita com os baixos preços pagos pelo SUS, e com os atrasos nos repasses dos recursos, preferia, na maioria das vezes, manter acordos simultâneos com os planos privados (medicina de grupo e seguro saúde); e, a segunda, caracterizou-se como um esquema não apenas alternativo ao SUS, mas rompido com ele. Sendo assim, a descentralização abraçada pela iniciativa privada tornouse eminentemente pró-mercado, isto é, voltada para consumidores e não para cidadãos.

São vários, por conseguinte, os tipos de obstáculo colocados contra a realização do SUS. Mas, nem só de obstáculos vive o Sistema. Além da existência da Constituição de 1988, a proposta inovadora que o diferencia do passado tem o respaldo dos seguintes fatores favoráveis:

- prévio incremento da capacidade instalada da rede de saúde, essencial ao seu desenvolvimento, consolidado a partir de 1987 com o advento do Sistema Unificado e Descentralizado de Saúde - Suds ${ }^{6}$ - (Soares, 1999, p. 242);

6 O Suds decorreu da implantação de medidas racionalizadoras da gestão da saúde e da preocupação em transferir os recursos federais para os Estados e Municípios. Com esse fim, em 1982, foi criado o Conselho Nacional de Assistência Médica da Previdência Social (Conasp). Dentre as providências tomadas pelo Conasp, destacam-se a criação do programa das Ações Integradas da Saúde (AIS), que permitiam o repasse dos recursos do Inamps para as esferas estaduais e municipais, através de convênios. As AIS alteraram as relações de poder entre União, Estados e Municípios e tiveram continuidade, a partir de 1986, com a criação do SUDS, "que funcionou como o principal instrumento de descentralização operacional, administrativa e financeira dos programas de saúde, entre 1987 e 1989" (Medici, 1996, p. 306). 
- a descentralidade fiscal entre as esferas de governo;

- a relativa independência das instâncias subnacionais quanto à arrecadação de tributos exclusivos;

- a criação, nas esferas municipais, de leis orgânicas que podem se sobrepor às leis ordinárias estaduais e federais (Viana, 274);

- a legitimidade de que desfruta nos círculos progressistas da sociedade ainda existentes;

- a transformação do Ministério Público em defensor dos direitos individuais e sociais indisponíveis.

Entretanto, sem o reforço do governo central na garantia da materialidade desse direito, especialmente no que se refere ao aspecto financeiro, dificilmente ele poderá ser concretizado como previsto. Isso remete novamente o balanço crítico feito até aqui para a questão do financiamento da área, dada a sua importância estratégica.

Viu-se que a Constituição de 1988 criou como instrumento básico de financiamento do Sistema de Seguridade Social um orçamento específico - o OSS -, de nível federal. Este orçamento seria composto basicamente de contribuição sociais, que tinham origem nas seguintes fontes: Cofins (Contribuição para o Financiamento da Seguridade Social), que substituiu o Finsocial; folha de salários, incidente sobre empresas e trabalhadores; lucro líquido das empresas; Pis/Pasep; e concursos de prognósticos. Esses recursos deveriam ser complementados com receitas provenientes do Orçamento Fiscal da União. Embora não estivesse prevista nenhuma vinculação de recursos para a saúde, como aconteceu com a educação, o art. 55, do Ato das Disposições Constitucionais Transitórias, estabelecia que "até que seja aprovada a Lei de Diretrizes Orçamentárias (LDO), 30\%, no mínimo, do orçamento da seguridade social, excluído o seguro-desemprego, serão destinados ao setor de saúde".

Isso propiciou recursos certos e regulares para a saúde até 1990. A partir de então, com a aprovação da LOS, a qual não definia quantias para a área, os recursos federias começaram a escassear. 
Como resultado, "a saúde passou a depender de uma série de fontes não convencionais", como foi o caso "de constantes empréstimos concedidos pelo [Fundo de Apoio ao Trabalhador] FAT" (Médici, 1996, p. 343). Enquanto isso, o OSS vinha sofrendo desvios de sua finalidade. Como já sinalizado, além do não adequado recolhimento das contribuições das empresas - o que implica sonegação -, e do aumento da economia informal - que escapa da obrigatoriedade de contribuição - grandes fatias desse orçamento eram utilizadas para cobrir despesas do Orçamento Fiscal (com inativos da União, com pagamento de pessoal e com a administração dos órgãos integrantes da Seguridade).

A conseqüência desse fato foi que a saúde, assim como a assistência social, viu-se à míngua de recursos financeiros, já que, por não ser contributiva, ficou impedida de usufruir da contribuição de empregadores e trabalhadores, que passou a ser exclusiva da previdência. Com isso, houve um revigoramento do conceito tradicional de seguridade, como sinônimo de seguro, em detrimento do conceito ampliado, incondicional e indisponível de segurança social, contido na Constituição. Esse problema agravouse com a fragmentação do locus institucional das três políticas, já que as mesmas situaram-se em Ministérios diferentes ${ }^{7}$ e foram coordenadas e geridas de forma desarticulada. Por ser o Ministério da Previdência o responsável pela arrecadação e fiscalização dos recursos da Seguridade, é obvio que incidiu sobre ele maior poder de concentração desses recursos.

Esses acontecimentos aprofundaram cada vez mais o estranhamento e a competição entre as três áreas, fazendo com que cada uma adotasse, isoladamente, estratégias de sobrevivência. No caso da saúde, foi emblemática a luta solitária do ex-ministro Adib Jatene (1995-1996) para criar uma fonte vinculada de recursos à área, através da instituição de uma contribuição adicional: a Contribuição Provisória sobre a Movimentação Financeira (CPMF). Nessa luta, em que nem mesmo o governo federal se envolveu, e muito menos a população, a aprovação da CPMF, depois de muitas dificuldades, expressou mais uma vez a falta de consenso e de

\footnotetext{
Apenas a assistência não se situou num Ministério próprio, ficando sob a coordenação de uma Secretaria de Estado de Assistência Social (SAS, hoje SEAS), pertencente ao Ministério da Previdência e Assistência Social.
} 
compreensão coletiva acerca do real significado do novo conceito de Seguridade Social.

Finalmente, no bojo da chamada Reforma do Estado, coordenada pelo ex-ministro da Administração, Bresser Pereira, no primeiro mandato do atual governo Cardoso (1995-1998; 19992002), a saúde, assim como as demais políticas sociais, passaram ter o seu caráter público reinterpretado.

O público, desde então, não foi mais entendido como sinônimo de res publica, isto é, coisa de todos, perante a qual, tanto o Estado como a sociedade, assumem papéis ativos e decisivos em prol do interesse comum; mas como um meio termo, ou melhor, um tertius interposto entre Estado e mercado, definido a partir da negação da intervenção estatal. Trata-se, por conseguinte, de um público não-estatal, na expressão reiterada de Bresser Pereira, e não propriamente não-mercantil; ou, em outras palavras, trata-se de um público que, no campo das políticas públicas, paradoxalmente recusa o Estado em ação, como produtor de bens e serviços e como um insubstituível garante de direitos.

É pelo negativo, portanto, que as políticas públicas assumem, no governo Cardoso, a expressão de um terceiro elemento - ou setor, para usar a linguagem tecnocrática atual - o qual seria dotado de lógica e racionalidade capazes de superar as limitações e a perda de efetividade do Estado. Identificadas como um novo ente jurídico, denominado Organizações Públicas não Estatais (Opnes), ou Organizações Sociais (OS), tais políticas, dentre as quais a saúde, teriam autonomia administrativa e financeira, bem como flexibilidade no seu funcionamento, o que pressupunha reforma constitucional.

Está-se diante, portanto, de uma noção de público que contraria os pressupostos da Constituição e do SUS e abre consideráveis flancos para a expansão da iniciativa privada, especialmente daquela guiada pela lógica mercantil. Não é por acaso, pois, que, o segmento privado lucrativo venha, nos últimos anos, apresentando grande versatilidade de ação, "entre elas a de oferta de vários tipos de planos com preços diferenciados segundo as condições de acomodação hospitalares e da abrangência da cobertura de procedimentos e das patologias" (Elias, 1997, p. 208). E tudo isso sem uma eficiente regulamentação e controle público. 


\section{Observações conclusivas}

Nos últimos dez anos as mudanças formais verificadas no âmbito da proteção à saúde no Brasil distinguiram-se principalmente por:

a) esforços de implantação de uma democracia extensiva caracterizada pela ampliação do direito de todos ao acesso incondicional e inegociável a bens e serviços de saúde;

b) esforços de estabelecimento de um novo compromisso entre as instâncias política e econômica em prol da qualidade de atendimento das necessidades da população.

Para pôr em prática esses intentos de cunho filosófico, um conjunto de mecanismos, canais e estratégias de decisões e gestões não convencionais foi arquitetado em favor da participação e do controle públicos.

Contudo, desde a sua concepção, o novo padrão de proteção à saúde conheceu uma renhida confrontação de interesses que reforçou a velha polarização entre as lógicas da rentabilidade econômica e da satisfação de necessidades humanas própria dos Sistemas de Seguridade Social capitalistas. A repentina mudança formal, sugerindo revisão radical na legislação, nas instituições e nas práticas sociais, encontrou não só resistências mas contra-ofensivas poderosas, porque apoiadas inclusive pelo governo central.

Com isso, não houve um processo coerente de definições e processamentos de políticas de seguridade social e nem de cada política de per si. Pelo contrário, houve e há um quadro marcado por desencontros, cisões e disputas. A Constituição da República vigente que deveria ser a fonte de recomendações políticas incontrastáveis, viu-se, desde a sua promulgação, desacreditada a partir dos governantes. E a proposta orgânica de Seguridade Social nela contida nunca teve pleno reconhecimento social.

Em vista disso, a intenção de se adotar uma agenda concertada e coerente de Seguridade Social no país, provocou um triplo enfrentamento conceitual e político de grandes repercussões na saúde: 
a) entre as concepções rivais - conservadoras e progressistas - referentes à regulamentação e à operacionalização da política;

b) entre os princípios da universalidade e da seletividade focalizada, norteadores da política;

c) entre a institucionalização e a privatização dos benefícios e serviços de saúde.

Esse triplo enfrentamento redundou na prevalência de uma contra-reforma conservadora, ratificadora dos seguintes impedimentos à criação de um Sistema Unificado de Saúde:

a) falta de vontade política do poder público;

b) falta de recursos;

c) excessiva permeabilidade da política às ingerências privadas;

d) persistência de centralidade política e de recursos na esfera federal;

e) falta de autonomia administrativa e financeira das instâncias subnacionais;

f) falta de efetiva regulamentação das atividades exploradas pela iniciativa privada.

Em suma, dada a persistência desse estado de coisas, é pouco provável, nos dias atuais, a formação de uma coalizão pró SUS. Para alcançar essa coalizão é preciso, novamente, que atores estrategicamente situados transformem a saúde em uma questão política e a mantenham, contra todas as adversidades, na agenda pública. Só assim os interesses conservadores prevalecentes continuarão sendo contestados e ameaçados na sua hegemonia. 


\section{Bibliografia}

ALMEIDA, Maria Hermínia T. de. Federalismo e políticas sociais. In: AFFONSO, Rui de Britto A.; SILVA, Pedro Luiz Barros (Orgs.). Descentralização e políticas sociais. São Paulo: FUNDAP, 1996. p.13-40.

ARRETCHE, Marta. Estado federativo e políticas sociais: determinantes da descentralização. Rio de Janeiro: Revan; São Paulo: FAPESP, 2000. $304 p$.

AZEVEDO, Sérgio de; ANDRADE, Luiz Aureliano G. de. A reforma do Estado e a questão federalista: reflexões sobre a proposta Bresser Pereira. In: DINIZ, Eli; AZEVEDO, Sérgio de (Orgs.). Reforma do Estado e democracia no Brasil. Brasília: Editora da Universidade de Brasília, 1997. 425p.

BRASIL. Constituição de 1988. Brasília: Senado Federal, Centro Gráfico, 1988.

BRAVO, Maria Inês S. As políticas brasileiras de seguridade social: Saúde. In: PROGRAMA de Capacitação Continuada para Assistentes Sociais. Capacitação em Serviço Social e política social, módulo 03. Brasília: CFESS-ABEPSS-CEAD/UnB, 2000. p. 103-115.

BRAVO, Maria Inês S.; Matos, Maurílio Castro de. A saúde no Brasil: reforma sanitária e ofensiva neoliberal. In: BRAVO, Maria Inês S.; PEREIRA, Potyara A. P. (Orgs.). Política social e democracia. São Paulo: Cortez; Rio de Janeiro: UERJ, 2001. p.197-215.

CUNHA, Rosani Evangelista da. Organização e gestão das políticas sociais no Brasil: o financiamento de políticas sociais no Brasil. In: PROGRAMA de Capacitação Continuada para Asistentes Sociais. Capacitação em Serviço Social e política social, módulo 03. Brasília: CFESS-ABEPSSCEAD/UnB, 2000. p.87-102.

ELIAS, Paulo Eduardo. Reforma e contra-reforma na proteção à saúde. Lua Nova, São Paulo, n. 40-41, p.193-215, 1997.

FAGNANI, Eduardo. Política social e pactos conservadores no Brasil. Cadernos FUNDAP, Desafios da gestão pública paulista, São Paulo, n. 21, p. 59-102, 1997.

MACEDO, Ubiratan Borges de. Os princípios fundamentais da Constituição de 1988. In: MERCADANTE, Paulo. Constituição de 1988: o avanço do retrocesso. Rio de Janeiro: Rio Fundo, 1990. p. 59-75.

MARX, Karl. Crítica ao Programa de Gotha. In: MARX, K.; ENGELS, F. Obras escogidas. Madrid: Ayuso, 1975. Tomo II, p. 5-41. 
MEDICI, André Cezar. Descentralização e gastos em saúde no Brasil. In: MEDICl, André Cezar. Descentralização e políticas sociais. São Paulo: FUNDAP, 1996. 376 p.

MONNERAT, Giselle L.; SOUZA, Rosimary Gonçalves; CASTRO, Mônica. Tendências atuais da descentralização e o desafio da democratização na gestão da saúde. In: BRAVO, Maria Inês S.; PEREIRA, Potyara A. P. (Orgs.). Política social e democracia. São Paulo: Cortez; Rio de Janeiro: UERJ, 2001. p. 67-85.

OZSLAK, Oscar; O’DONNELL, Guillermo. Estado y políticas estatales en America Latina: hacia uma estrategia de investigación. 1976. 46 p. (Documento CEDES/ G.E, CLACSO, n. 4).

PEREIRA, Luís Carlos Bresser; GRAU, Nuria C. (Orgs). O público não-estatal na reforma do Estado. Rio de Janeiro: CLAD/FGV, 1999. 498p.

PEREIRA, Potyara A. P. A política social no contexto da seguridade social e do welfare state: a particularidade da assistência social. Serviço Social \& Sociedade, São Paulo, v. 19, n. 56, p. 60-76, mar. 1998.

. Centralização e exclusão social: duplo entrave à política de assistência social. Ser Social, Brasília, n. 3, p. 119-133, jul./dez. 1998.

PISÓN, José Martinez de. Políticas de bienestar: um estúdio sobre los derechos sociales. Madrid: Tecnos, 1998.

SOARES, Laura Tavares Ribeiro. Ajuste neoliberal e desajuste social na América Latina. Rio de Janeiro: UFRJ, 1999.

VIANA, Ana Luíza D'Ávila. SUS: entraves à descentralização e propostas de mudanças. In: AFFONSO, Rui de Britto A.; SILVA, Pedro Luiz Barros (Orgs.). Descentralização e políticas sociais. São Paulo: FUNDAP, 1996. 